\title{
PROTOTYPE SISTEM MONITORING LEVEL AIR BERBASIS LABVIEW \& ARDUINO SEBAGAI SARANA PENDUKUNG PRAKTIKUM INSTRUMENTASI SISTEM KENDALI
}

\author{
Hery Suryantoro ${ }^{1}$, Almira Budiyanto ${ }^{2}$ \\ ${ }^{1}$ Jurusan Teknik Elektro, Fakultas Teknologi Industri, Universitas Islam Indonesia, \\ Yogyakarta,035204405@uii.ac.id \\ ${ }^{2}$ Jurusan Teknik Elektro, Fakultas Teknologi Industri, Universitas Islam Indonesia, \\ Yogyakarta,155240103@uii.ac.id
}

Submisi: 23 Oktober 2018 ; Penerimaan: 17 Juli 2019

\begin{abstract}
ABSTRAK
Air adalah kebutuhan yang sangat penting, ketersediaan air tetap harus selalu ada baik di rumah tangga, perkantoran, tempat-tempat umum ataupun industri. Hal ini menyebabkan peran tangki penampung air fundamental untuk menjamin ketersediaan air. Pengukuran ketinggian air secara otomatis adalah salah satu parameter yang perlu diukur untuk mendeteksi keadaan tangki penampung yang meluap atau kosong. Salah satunya dengan membuat sensor pengukur level air yang diumpanbalikkan menggunakan pompa air. Pada penelitian ini dibuat prototipe dengan menggunakan Arduino Uno R3 dan software LabVIEW sebagai pusat pengolah data yang terintegrasi dengan sensor ultrasonic SRF05 sebagai pembaca ketinggian air. Prototipe ini dilengkapi dengan indikator kondisi air, indikator pompa air yang diatur dari Arduino. Metode yang digunakan pada penelitian ini yaitu perencanaan, pengumpulan bahan, perancangan hardware, pembuatan program Arduino dan LabView, pengujian. Pengambilan data dilakukan dengan mengubah level air dengan membuka kran secara bertahap. Berdasarkan hasil pengamatan didapatkan hasil perbandingan antara level air yang tertera pada tangki penampung air dengan level air yang tertampil pada monitoring Arduino dan LabVIEW yaitu level air penampung $22 \mathrm{~cm}$ hasil sistem monitoring 22,12 $\mathrm{cm}$, level air $15,5 \mathrm{~cm}$ hasil sistem monitoring $14,47 \mathrm{~cm}$, level air $2,5 \mathrm{~cm}$ hasil sistem monitoring $2,52 \mathrm{~cm}$. Rata-rata kesalahan pembacaan pengukuran level air sebesar $0,089 \mathrm{~cm}$.
\end{abstract}

Kata kunci: Tangki Penampung; Sensor Ultrasonic; Level Air; Arduino Uno; LabVIEW

\section{PENDAHULUAN}

Air mempunyai peranan sangat penting dalam kelangsungan kehidupan makhluk hidup didunia dan merupakan salah satu kebutuhan pokok yang harus ada setiap harinya. Air akan sangat bermanfaat bagi kehidupan di bumi dalam jumlah yang proporsional. Manusia memanfaatkan air untuk berbagai kebutuhan, pada rumah tangga misalnya untuk dikonsumsi, mandi, mencuci dan sebagainya. Selain itu, air juga digunakan pada industri untuk pembangkit listrik tenaga air, transportasi, irigasi dan lain-lain.
Jumlah air yang kurang atau berlebihan dapat berdampak berbagai hal. Contoh pada industri kimia terdapat proses pemisahan cairan (destilasi) yang membutuhkan pengaturan level ketinggian cairan, apabila ada perubahan (deviasi) laju aliran masukan yang disebabkan perubahan tekanan aliran inlet atau juga disebabkan timbulnya gaya gesek pada pipa saluran, maka akan mengakibatkan perubahan debit masukan yang membuat level cairan berubah-ubah. Masalah yang muncul ketika level ketinggian cairan dalam tangki penampung tidak diketahui, sehingga 
dimungkinkan terjadi keadaan tangki penampung yang meluap atau kosong dikarenakan kurangnya pengawasan terhadap tangki penampung. Hal ini dapat mengganggu stabilitas dalam proses pemisahan cairan tersebut.

Pada penelitian ini akan dirancang prototype sistem monitoring level air berbasis LabVIEW dan Arduino dengan menggunakan sensor ultrasonik yaitu dengan memanfaatkan cepat rambat gelombang ultrasonik pada udara. Penggunaan sensor ultrasonik memiliki keuntungan yaitu dapat mengukur level ketinggian air tanpa bersentuhan dengan airnya.

\section{TINJAUAN PUSTAKA \\ Sistem Monitoring}

Sistem monitoring adalah sistem yang sangat diperlukan dalam sebuah aplikasi. Sistem monitoring disini berperan sebagai pemberi data yang nantinya akan diproses lebih lanjut setelah data terkirim dari sebuah sistem monitoring. Sistem monitoring berasal dari bahasa Inggris yaitu "Monitor System "yang dalam bahasa Indonesianya adalah sistem pemantauan. Dalam kehidupan seharihari, sistem pemantauan banyak dilakukan penerapannya dan umumnya dilakukan sebagai bentuk tindakan pencegahan.

Sistem monitoring mempunyai dua bentuk konfigurasi data:

1. Konfigurasi data untuk aplikasi monitor itu sendiri.

2. Konfigurasi data untuk sistem yang dipantau.

\section{Level}

Level dalam penelitian ini adalah merupakan level air atau ketinggian air dalam sebuah tempat. Pengukuran level air ini sendiri adalah untuk mengetahui ketinggian air dalam sebuah tempat maupun di alam bebas seperti sungai dan lain-lain. Pengukuran level sendiri banyak dimanfaatkan untuk mengetahui sudah tepat belumkah ukuran level air didalam sebuah tangki, selain itu saat ini banyak digunakan untuk mengetahui ketinggian air sungai untuk mendeteksi banjir. Pengukuran level dapat dilakukan dengan berbagai cara dengan pengukuran manual maupun dengan menggunakan sebuah sensor. Oleh karena itu pengukuran level sangat penting, kegagalan dalam pengukuran level akan berakibat buruk bahkan dapat membahayakan keselamatan.

\section{Sensor Ultrasonik}

Sensor ultrasonik adalah sensor yang berfungsi untuk merubah besaran fisis (suara) menjadi besaran listrik maupun sebaliknya yang dikonversi menjadi jarak. Konsep dasar dari sensor ini yaitu memanfaatkan prinsip pemantulan gelombang suara yang dapat diaplikasikan untuk menghitung jarak benda dengan frekuensi yang ditentukan sesuai dengan sumber oscilator. Disebut sebagai sensor ultrasonik dikarenakan sensor ini mengaplikasikan gelombang ultrasonik sebagai trandusernya.

\section{Sensor Ultrasonik SRF05}

SRF05 merupakan sensor

pengukur jarak yang menggunakan ultrasonik. Prinsip kerja sensor ultrasonik SRF05 ditunjukkan pada Gambar 1. Dimana prinsip kerja sensor ultrasonik ini adalah pemancar (transmitter) mengirimkan seberkas gelombang ultrasonik, lalu diukur waktu yang dibutuhkan hingga datangnya pantulan dari obyek. Lamanya waktu ini sebanding dengan dua kali jarak sensor dengan obyek, sehingga didapat jarak sensor dengan obyek yang bisa ditentukan dengan persamaan 1 .

Jarak $=\frac{\text { Kecepatan suara } x \text { waktu pantul }}{2}$ 




Gambar 1. Prinsip Kerja Sensor Ultrasonik

Pada dasanya, sensor PING terdiri dari sebuah chip pembangkit sinyal $40 \mathrm{KHz}$, sebuah speaker ultrasonik dan sebuah mikropon ultrasonik ditunjukan pada Gambar 2. Speaker ultrasonik mengubah sinyal $40 \mathrm{KHz}$ menjadi suara sementara mikropon ultrasonik berfungsi untuk mendeteksi pantulan suaranya. Sensor PING mendeteksi jarak obyek dengan cara memancarkan gelombang ultrasonik $(40 \mathrm{kHz})$ selama tBURST $(200 \mu \mathrm{s})$ kemudian mendeteksi pantulannya. Sensor PING memancarkan gelombang ultrasonik sesuai dengan kontrol dari mikrokontroler pengendali (pulsa trigger dengan tOUT min. $2 \mu \mathrm{s})$. Sensor ultrasonik SRF05 ditunjukan seperti pada Gambar 2.



Gambar 2. Sensor Ultrasonik SRF 05 (Sumber : Datasheet SRF05 Module)

\section{Arduino Uno}

Menurut Feri Djuandi (2011:8)

Komponen utama didalam papan Arduino adalah sebuah mikrokontroler 8 bit dengan merk ATmega yang dibuat oleh Atmel Corporation. Arduino memiliki 14 pin input/output yang mana 6 pin dapat digunakan sebagai output
PWM, 6 analog input, crystal osilator 16 $\mathrm{MHz}$, koneksi USB, jack power, kepala ICSP, dan tombol reset. Arduino mampu mensupport mikrokontroller; dapat dikoneksikan dengan komputer menggunakan kabel USB.Board mikrokontroler Arduino ditunjukkan pada Gambar 3.



Gambar 3. Board Mikrokontroller Arduino Uno

(Sumber: Feri Djuandi 2011:8)

\section{LCD (Liquid Crystal Display)}

LCD (Liquid Crystal Display) merupakan rangkaian elektronika yang digunakan untuk menampilkan keterangan atau indikator yang diberikan kedalam mikrokontroler. LCD ditunjukan pada Gambar 4. LCD sudah digunakan diberbagai bidang misalnya alal-alat elektronik seperti televisi, kalkulator, atau pun layar komputer. Pada postingan aplikasi LCD yang digunakan yaitu LCD dot matrik dengan jumlah karakter $2 \times 16$. LCD sangat berfungsi sebagai penampil yang nantinya akan digunakan untuk menampilkan status kerja alat.



Gambar 4. LCD (Liquid Crystal Display) (Sumber: Data sheet LCD Module)

\section{I2C LCD}

I2C LCD adalah modul LCD yang dikendalikan secara serial sinkron dengan protokol I2C/IIC (Inter Integrated Circuit) atau TWI (Two Wire Interface). Modul LCD pada normalnya dikendalikan secara paralel baik untuk jalur data maupun kontrolnya. Namun 
jalur paralel akan memakan banyak pin di sisi kontroller (misal Arduino, komputer ,dll). Setidaknya akan membutuhkan 6 atau 7 pin untuk mengendalikan sebuah modul LCD. Dengan demikian untuk sebuah kontroller yang harus mengendalikan banyak $\mathrm{I} / \mathrm{O}$, menggunakan jalur paralel adalah solusi yang kurang tepat.

Modul I2C converter diperlihatkan pada Gambar 5 ini menggunakan chip ICPCF8574 produk dari NXP sebagai kontrolernya. IC ini adalah sebuah 8 bit I/O expander for $12 \mathrm{c}$ bus yang pada dasarnya adalah sebuah shift register.



Gambar 5. Modul I2C LCD

(Sumber: Data sheet I2C Module)

\section{Driver Relay}

Relay adalah saklar yang dikendalikan secara elektro-mekanik (electromechanical switch). Arus listrik yang mengalir pada kumparan relay akan menciptakan medan magnet yang kemudian akan menarik lengan relay dan mengubah posisi saklar, yang sebelumnya terbuka menjadi terhubung. Relay memiliki tiga jenis kutub: COMMON = kutub acuan, NC (Normally Close) = kutub yang dalam keadaan awal terhubung pada COMMON, dan NO $($ Normally Open $)=$ kutub yang pada awalnya terbuka dan akan terhubung dengan COMMON saat kumparan relay diberi arus listrik.



Gambar 6. Driver Relay

(Sumber: Data sheet Driver Relay Module)

\section{LabVIEW}

LabVIEW (Laboratory Virtual Instrumentation Engineering Workbench), merupakan instrumentasi virtual yang diproduksi oleh National Instruments, berupa sebuah sistem perangkat lunak yang dikembangkan dengan tujuan utama untuk akuisisi data dan sistem kontrol yang berbasis pemrograman grafik secara real time. LabView merupakan bahasa pemrograman secara grafis yang ditunjukan pada Gambar 7, dengan menggunakan icon yang dihubungkan oleh suatu garis (wire) untuk menciptakan suatu aplikasi LabView (Virtual Instrument, VI). Dengan LabView dapat didesain virtual instruments dengan membuat grafik interface dilayar komputer yang memungkinkan untuk mengoperasikan program instrument, mengontrol hardware, menganalisa data dan menampilkan hasil.

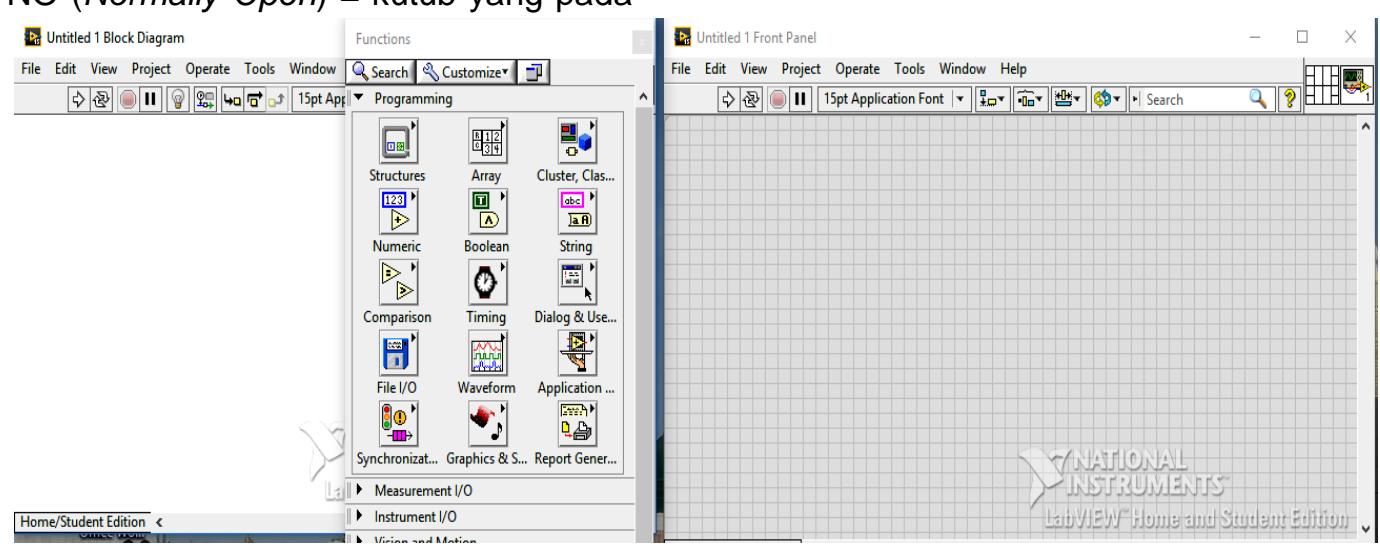

Gambar 7. Software LabVIEW 


\section{METODE PENELITIAN}

Dalam melakukan penelitian ini dipergunakan metode rancang bangun serta pengumpulan data informasi yang didapat dari analisis hasil yang diberikan oleh alat. Sebelum merealisasikan alat terlebih dahulu menyusun perancangan sistem secara utuh agar tujuan dari penelitian dapat tercapai. Penelitian ini dibagi beberapa tahapan yang nantinya akan diimplementasikan langkah demi langkah yaitu: perencanaan, pengumpulan bahan, perancangan hardware, pembuatan program akuisisi data level dengan mikrokontroller Arduino dan LabVIEW, pengujian dan analisis.

\section{Sistem}

Secara umum sistem monitoring level air berbasis LabVIEW dan Arduino ditunjukkan pada blok diagram Gambar 8. Pengukuran level air ini adalah untuk mengetahui ketinggian air dalam sebuah tangki penampung, dengan mengisi air ke tangki penampung sampai batas tertentu dan mengurangi levelnya secara bertahap melalui kran manual, komponen utama terdiri dari sensor ultrasonik SRF05 yang difungsikan sebagai sensor pengukur level cairan pada suatu tangki, sedangkan Arduino digunakan untuk mengolah data dari sensor ultrasonik dalam membaca sensor level air yang ditampilkan melalui LCD dan LabVIEW.



Gambar 8. Blok Diagram Sistem

\section{Skematik Rangkaian}

Setelah membuat diagram blok sebagai alur rakitan komponen, selanjutnya membuat rangkaian yang digunakan sebagai sistem monitoring level air dari modul yang satu dengan modul yang lain agar dapat berinteraksi melalui port dan pin yang ada dengan menggunakan kabel jumper sebagai penghubung setiap pin dan port yang ada seperti pada Gambar 9.



Gambar 9. Skematik Diagram Rangkaian

Pada perancangan hardware ini dibuat rangkaian keseluruhan sistem dari mikrokontroller Arduino yang dihubungkan dengan sensor ultrasonik SRF05 untuk mengukur level, I2C LCD $16 \times 2$ sebagai tampilan pembacaan, 
modul relay, pompa air untuk mengisi air kedalam tangki dan komputer yang sudah dilengkapi dengan program LabVIEW untuk monitoringnya.

\section{Karakteristik Sensor Ultrasonik SRF05}

Dalam penelitian ini langkah awal yang dilakukan adalah membaca informasi datasheet dan mengoleksi informasi penting yang diperlukan dalam menggunakan sebuah sensor ultrasonik SRF05. Dalam hal ini diharapkan dapat mengetahui bagaimana prinsip kerjanya.



Gambar 10. Prinsip Kerja Sensor

$$
\text { Ultrasonik }
$$

Sensor ultrasonik SRF05 adalah alat yang terdiri dari 2 unit yaitu unit pemancar dan unit penerima, unit pemancar akan memancarkan gelombang ultrasonik melalui medium udara, jika gelombang tersebut mengenai suatu objek, maka gelombang akan dipantulkan kembali dan diterima oleh unit penerima pada sensor, sehingga akan menghasilkan tegangan bolak-balik dengan frekuensi yang sama. Pantulan gelombang ultrasonik



Gambar 12. Sensor Ultrasonik SRF05 Sebagai Pengukur Level Air $(y=J a r a k$ sensor dengan permukaan tangki, $x=$ jarak sensor dengan permukaan air, $h=y-x$ ) tersebut dapat dimanfaatkan untuk mengukur jarak antara sensor.

Desain Rangkaian Sensor dan Akuisisi Data Level Dengan Arduino

Langkah berikutya dalam penelitian ini adalah merancang rangkaian sensor ultrasonik SRF05 untuk mengukur level serta membangun sistem akuisisi data berbasis mikrokontroller Arduino untuk menampilkan hasil pengukuran tersebut. Dalam pengukuran level sensor ultrasonik SRF05 dihubungkan dengan mode separate echo and trigger, seperti pada gambar 11 .


Gambar 11. Rangkaian Sensor Ultrasonik SRF05

Sensor ultrasonik SRF05 jika difungsikan sebagai sensor pengukur level cairan pada suatu tangki maka konfigurasi sensor ultrasonik dapat dipasang seperti pada gambar 12



Tangki air 


\begin{tabular}{lll}
\multicolumn{1}{c}{ Untuk pembacaan hasil } & berfungsi untuk mensetting pin yang \\
pengukuran sensor ultrasonik SRF05 & akan digunakan sesuai dengan \\
tersebut membuat program arduino & kebutuhan, dengan software tersebut \\
dengan menggunakan software & dapat dilihat pembacaan sensor dengan \\
arduino.ide. Pembuatan program & memanfaatkan serial monitor yang \\
Arduino ini sendiri dimulai dengan & tersedia atau pada tampilan LCD seperti \\
menginisialisasi pin-pin mana saja yang & pada gambar 13.
\end{tabular}
akan digunakan oleh sistem. Inisialisasi


Gambar 13. Program Pembacaan Jarak Sensor Dengan Permukaan Air



Gambar 14. Program Pengukur Level Ketinggian Air 


\section{Desain Akuisisi Data Level Dengan Lab VIEW}

LabVIEW merupakan pemograman berbasis visual yang terdapat jendela front panel sebagai tampilan indikator dan input saja dan jendela blok diagram sebagai tempat membuat programnya. Pada tahap ini membangun sistem akuisisi data dengan membuat grafik


Gambar 15. Block Diagram dan Front Panel Pengukuran Level Air

Block diagram merupakan tempat pembuatan kode program. Program disini dilakukan dengan cara menempatkan beberapa node dan menghubungkannya satu sama lain. Front panel adalah tampilan program yang digunakan untuk berinteraksi dengan pengguna. Objek-objek pada front panel akan secara otomatis memiliki representasi ikonnya di block diagram, khususnya untuk objek-objek yang membawa data, baik data yang masuk dari pengguna ke program maupun data yang keluar ke program

Untuk dapat berkomunikasi dengan Arduino, LabVIEW memerlukan tambahan perangkat lunak, yaitu VISA (The Virtual Instrument Software) yang merupakan perangkat lunak untuk konfigurasi, pemrograman dan troubleshooting sistem instrumentasi, $P X I$, serial, ethernet dan USB interface.

\section{Sistem Kerja Prototype Alat}

Secara umum sistem monitoring level air berbasis $L a b$ VIEW dan Arduino seperti pada gambar 16 . interface dilayar komputer untuk menampilkan hasil pengukuran level air seperti ditunjukan Gambar 15. Pengukuran level air yang dihasilkan oleh sensor ultrasonik SRF05 akan diolah Arduino lalu dikirim ke LabVIEW dalam bentuk data serial untuk diolah dan ditampilkan oleh Lab View



Gambar 16. Prototype Sistem Monitoring Level Air

Pengukuran level air ini adalah untuk mengetahui ketinggian air dalam sebuah toples yang difungsikan sebagai tangki penampung air. Pada penampung air di beri alat pendeteksi level yaitu sensor ultrasonik SRF05 yang di maksudkan untuk mengukur level air pada tangki penampung tersebut, tepatnya sensor ultrasonik berada di atas. Tangki penampung didesain menjadi 2 yaitu atas dan bawah. Tangki penampung bawah berfungsi untuk menampung air dan menyalurkan air pada tangki yang 
diatas. Untuk menyalurkan tangki atas diperlukan pompa untuk menyedot air yang berada di tangki bawah. Tangki penampung atas berfungsi sebagai pendeteksi air pada ketinggian tersebut yang tujuan nya untuk mengukur level air pada tangki penampungan tersebut.

Pengukuran level air dilakukan dengan mengubah level air didalam tangki atas secara bertahap yaitu membuka kran secara manual. Langkah pertama yang harus dilakukan adalah mengisi air didalam tangki setinggi 22 $\mathrm{cm}$, setelah itu mengurangi level air secara bertahap sebesar $0,5 \mathrm{~cm}$ dengan membuka kran. Pada prototype ini juga dilengkapi dengan indikator air pada posisi rendah, menengah dan penuh yang diumpanbalikan ke pompa air, apabila kondisi air dibawah $2 \mathrm{~cm}$ maka pompa air akan otomatis hidup mengisi tangki hingga setinggi $23 \mathrm{~cm}$, pompa akan otomatis mati jika kondisi air penuh , perubahan level air dalam tangki dimonitoring melalui Arduino dan Lab VIEW secara real time.

\section{HASIL DAN PEMBAHASAN Pengujian Sensor Ultrasonik SRF05}

Pengujian ini dilakukan dengan mengisi air kedalam tangki setinggi 22 $\mathrm{cm}$, dan mengurangi level air sebesar $0,5 \mathrm{~cm}$ secara bertahap, dari hasil pengukuran dapat dilihat pada Tabel 1 , bahwa sensor ultrasonik SRF05 membaca jarak dari sensor ultrasonik ke permukaan air.

Tabel 1. Hasil Pengukuran Jarak Sensor Ultrasonik SRF05

\begin{tabular}{|c|c|c|c|}
\hline No & $\begin{array}{c}\text { Level air } \\
(\mathbf{c m})\end{array}$ & $\begin{array}{c}\text { Jarak tertampil pada } \\
\text { monitoring serial }(\mathbf{c m}) \mathbf{x}\end{array}$ & $\begin{array}{c}\text { Jarak } \mathbf{( c m}) \\
\mathbf{y}\end{array}$ \\
\hline 1 & 22 & 5,88 & \\
2 & 21,5 & 6,34 & \\
3 & 21 & 7,29 & \\
4 & 20,5 & 7,88 & \\
5 & 20 & 8,34 & \\
6 & 19,5 & 8,65 & \\
7 & 19 & 9,22 & \\
8 & 18,5 & 9,65 & \\
9 & 18 & 10,28 & \\
10 & 17,5 & 10,66 & \\
11 & 17 & 11,22 & 28,5 \\
12 & 16,5 & 11,28 & \\
13 & 16 & 11,84 & \\
14 & 15,5 & 12,74 & \\
15 & 15 & 13,22 & \\
16 & 14,5 & 13,43 & \\
17 & 14 & 14,21 & \\
18 & 13,5 & 14,26 & \\
19 & 13 & 15,21 & \\
20 & 12,5 & 15,69 & \\
21 & 12 & 16,26 & \\
\hline
\end{tabular}

Dari tabel 1 dapat dilihat bahwa nilai level berbanding terbalik dengan jarak tertampil di monitoring serial. Karena dihitung dengan mengurangi jarak dasar tangki ke sensor dengan jarak sensor ke permukaan air, sehingga semakin besar nilai level maka nilai jarak tertampil akan semakin kecil. Untuk menentukan jarak dimasukkan rumus $\quad \mathrm{x}=$ durration/koeff, hal

\begin{tabular}{|c|c|c|c|}
\hline No & $\begin{array}{c}\text { Level air } \\
(\mathbf{c m})\end{array}$ & $\begin{array}{c}\text { Jarak tertampil pada } \\
\text { monitoring serial (cm) } \mathbf{x}\end{array}$ & $\begin{array}{c}\text { Jarak (cm) } \\
\mathbf{y}\end{array}$ \\
\hline 22 & 11,5 & 16,72 & \\
23 & 11 & 16,88 & \\
24 & 10,5 & 17,65 & \\
25 & 10 & 18,14 & \\
26 & 9,5 & 18,62 & \\
27 & 9 & 19,14 & \\
28 & 8,5 & 19,67 & \\
29 & 8 & 20,09 & \\
30 & 7,5 & 20,66 & \\
31 & 7 & 21,02 & \\
32 & 6,5 & 21,6 & \\
33 & 6 & 22,53 & \\
34 & 5,5 & 22,66 & \\
35 & 5 & 23,07 & \\
36 & 4,5 & 23,5 & \\
37 & 4 & 23,95 & \\
38 & 3,5 & 24,43 & \\
39 & 3 & 25,05 & \\
40 & 2,5 & 25,53 & \\
41 & 2 & 26,05 & \\
\hline
\end{tabular}

ini dilakukan karena dari prinsip kerja sensor SRF05 tersebut adalah mengukur waktu tempuh gelombang suara yang dipantulkan oleh sensor. Dari pengukuran didapatkan nilai $\mathrm{x}$, dimana $x$ tersebut adalah jarak antara permukaan air dengan sensor SRF05 dan $y$ adalah jarak antara sensor dengan permukaan tangki sebesar 28.5 $\mathrm{cm}$. Gambar 17 menunjukan 
pengukuran jarak antara sensor SRF 05 dengan permukaan air.



Gambar 17. Pengukuran Jarak Sensor Dengan Permukaan Air

\section{Pengujian Akuisisi Data Dengan Arduino dan Lab VIEW \\ Pada pengujian ini dilakukan} kembali dengan mengisi air kedalam tangki setinggi $22 \mathrm{~cm}$, dan mengurangi level air sebesar $0,5 \mathrm{~cm}$ secara bertahap, dan memasukan persamaan konversi jarak ke level air pada program Arduino yaitu $h=y-x$, dimana, $\mathrm{h}$ adalah level air, y adalah jarak antara sensor dengan permukaan tangki yaitu $28,5 \mathrm{~cm}$ dan $x$ adalah jarak antara sensor dengan permukaan air. Hasil pengukuran level air sensor ultrasonik SRF05 dengan Arduino dan Lab VIEW diperlihatkan pada Tabel 2 ..

Tabel 2. Hasil Pengukuran Level Air Dengan Arduino Dan Lab VIEW

\begin{tabular}{|c|c|c|c|c|}
\hline No & $\begin{array}{c}\text { Level air } \\
(\mathrm{cm})\end{array}$ & $\begin{array}{c}\text { Level tertampil pada } \\
\text { monitoring Lab VIEW } \\
(\mathrm{cm})\end{array}$ & $\begin{array}{c}\text { Level tertampil pada } \\
\text { monitoring LCD } \\
(\mathrm{cm})\end{array}$ & Error (cm) \\
\hline 1 & 22 & 22,12 & 22,12 & 0,12 \\
2 & 21,5 & 21,66 & 21,66 & 0,16 \\
3 & 21 & 21,17 & 21,17 & 0,17 \\
4 & 20,5 & 20,22 & 20,22 & 0,28 \\
5 & 20 & 19,83 & 19,83 & 0,17 \\
6 & 19,5 & 19,48 & 19,48 & 0,02 \\
7 & 19 & 18,95 & 18,95 & 0,05 \\
8 & 18,5 & 18,47 & 18,47 & 0,03 \\
9 & 18 & 18,29 & 18,29 & 0,29 \\
10 & 17,5 & 17,36 & 17,36 & 0,14 \\
11 & 17 & 16,88 & 16,88 & 0,12 \\
12 & 16,5 & 16,72 & 16,72 & 0,22 \\
13 & 16 & 15,95 & 15,95 & 0,05 \\
14 & 15,5 & 15,47 & 15,47 & 0,03 \\
15 & 15 & 14,95 & 14,95 & 0,05 \\
16 & 14,5 & 14,48 & 14,48 & 0,02 \\
17 & 14 & 13,97 & 13,97 & 0,03 \\
18 & 13,5 & 13,48 & 13,48 & 0,02 \\
19 & 13 & 12,95 & 12,95 & 0,05 \\
20 & 12,5 & 12,43 & 12,43 & 0,07 \\
21 & 12 & 11,95 & 11,95 & 0,05 \\
& & & & \\
\hline
\end{tabular}

\begin{tabular}{|c|c|c|c|c|}
\hline No & $\begin{array}{l}\text { Level air } \\
(\mathrm{cm})\end{array}$ & $\begin{array}{l}\text { Level tertampil pada } \\
\text { monitoring Lab VIEW } \\
\text { (cm) }\end{array}$ & $\begin{array}{l}\text { Level tertampil pada } \\
\text { monitoring LCD } \\
(\mathrm{cm})\end{array}$ & $\begin{array}{l}\text { Error } \\
(\mathrm{cm})\end{array}$ \\
\hline 22 & 11,5 & 11,48 & 11,48 & 0,02 \\
\hline 23 & 11 & 10,88 & 10,88 & 0,12 \\
\hline 24 & 10,5 & 10,79 & 10,79 & 0,29 \\
\hline 25 & 10 & 10,33 & 10,33 & 0,33 \\
\hline 26 & 9,5 & 9,45 & 9,45 & 0,05 \\
\hline 27 & 9 & 8,97 & 8,97 & 0,03 \\
\hline 28 & 8,5 & 8,4 & 8,4 & 0,1 \\
\hline 29 & 8 & 7,91 & 7,91 & 0,09 \\
\hline 30 & 7,5 & 7,45 & 7,45 & 0,05 \\
\hline 31 & 7 & 6,97 & 6,97 & 0,03 \\
\hline 32 & 6,5 & 6,47 & 6,47 & 0,03 \\
\hline 33 & 6 & 5,98 & 5,98 & 0,02 \\
\hline 34 & 5,5 & 5,47 & 5,47 & 0,03 \\
\hline 35 & 5 & 4,93 & 4,93 & 0,07 \\
\hline 36 & 4,5 & 4,47 & 4,47 & 0,03 \\
\hline 37 & 4 & 3,95 & 3,95 & 0,05 \\
\hline 38 & 3,5 & 3,47 & 3,47 & 0,03 \\
\hline 39 & 3 & 2,9 & 2,9 & 0,1 \\
\hline 40 & 2,5 & 2,52 & 2,52 & 0,02 \\
\hline 41 & 2 & 1,95 & 1,95 & 0,05 \\
\hline \multicolumn{4}{|c|}{ Rata-rata kesalahan } & 0,089 \\
\hline
\end{tabular}

Hasil pengukuran diperlihatkan pada Tabel 2 bahwa adanya perbedaan atau selisih yang kecil antara level air yang tertera pada tangki penampung dengan level yang tertampil pada monitoring LCD dan LabVIEW. Ratarata kesalahan pembacaan pengukuran sensor adalah $0.089 \mathrm{~cm}$. Hal ini bisa disebabkan karena sudut pantul yang dihasilkan sensor ultrasonik SRF05 tidak selalu sama dan permukaan air yang tidak rata ketika level air dikurangi secara bertahap. Sistem ini bekerja secara otomatis sesuai dengan aktifitas ketinggian air yang di baca oleh sensor ultrasonik SRF05. Setiap perpindahan level air akan ditampilkan pada LCD dan LabVIEW, tergantung pengguna mengatur berapa $\mathrm{cm}$ data akan ditampilkan. 

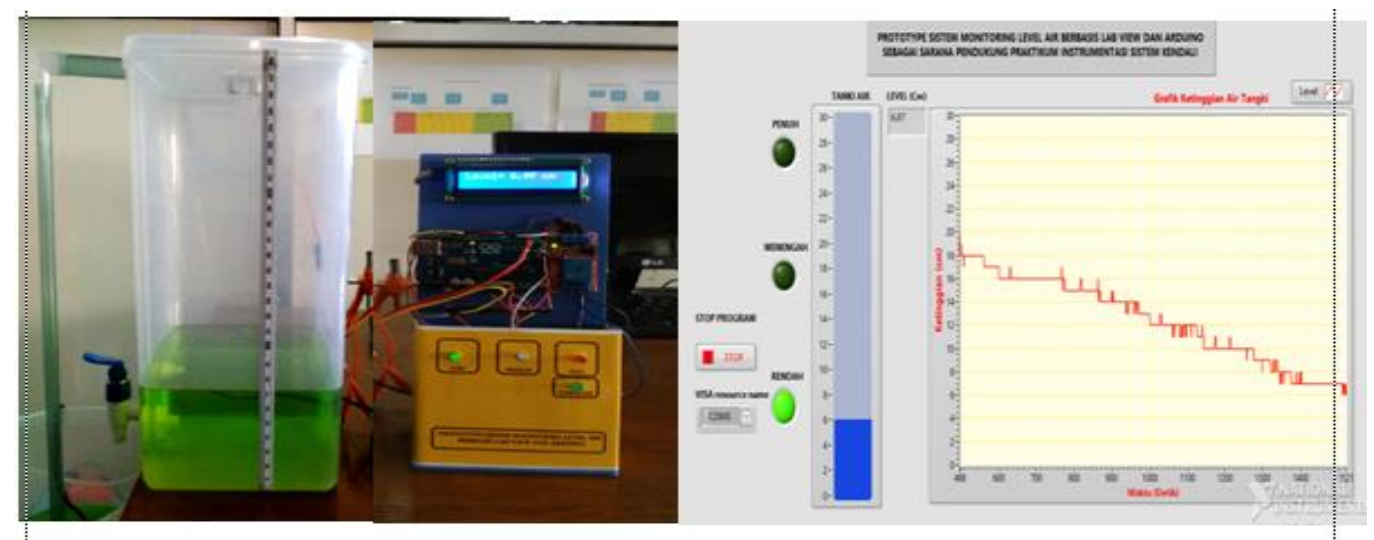

Gambar 18. Pengukuran Level Air dengan Arduino dan LabVIEW

Pada Gambar 18 setiap perubahan level air akan dibaca oleh sensor SRF05 kemudian data dikirimkan ke Arduino dan akan ditampilkan pada LCD Arduino dan LabVIEW.

\section{Pengujian Indikator Level Air LabVIEW dan Arduino}

Hasil desain prototipe berbasis LabView dan Arduino ini diuji coba menggunakan modul sistem monitoring yang dirakit. Langkah pertama menguji program monitoring menggunakan Arduino dan GUI Labview adalah menghubungkan modul mikrokontroler
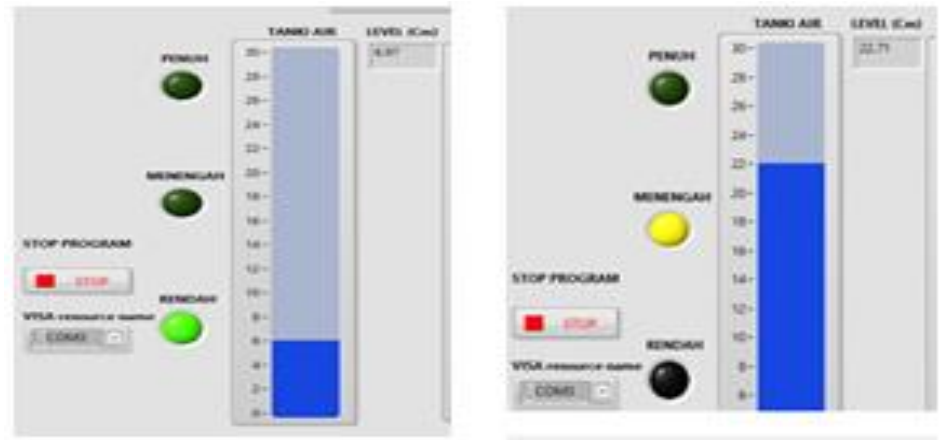

Gambar 19. Front Panel
LabVIEW akan dapat

Program LabVIEW akan dapat port serial yang ada. Dalam penelitian ini digunakan port COM 3 dan dengan pengaturan baud rate 9600 . Hal ini dilakukan untuk sinkronisasi antara Arduino dan LabVIEW.

Prototipe ini dilengkapi tiga indikator LED yaitu: hijau (low), kuning
Arduino yang sudah terpasang sensor ultrasonik SRF05 melalui kabel USB. Untuk dapat berkomunikasi dengan Arduino, LabVIEW memerlukan tambahan perangkat lunak, yaitu VISA (The Virtual Instrument Software). VISA menyediakan antar muka pemrograman antara LabVIEW dengan Arduino. Saat sensor ultrasonik SRF05 membaca level air maka akan muncul data pada jendela front panel LabView dan pada LCD serta indikator LED. Tampilan jendela front panel LabView dan Arduino monitoring level air bisa dilihat pada Gambar 19 dan Gambar 20.

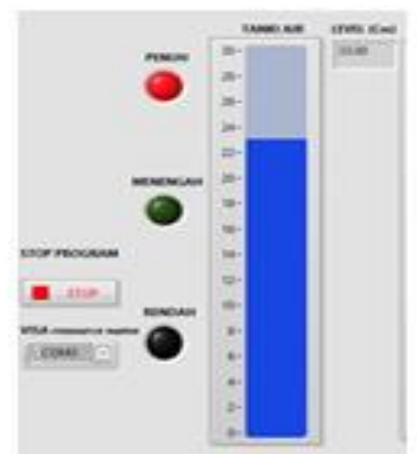

IEW Monitoring Level Air

(medium), merah (full), LED ini berfungsi untuk memberi informasi kepada pengguna tentang ketinggian air berada pada kondisi rendah, menengah atau penuh, dan juga satu indikator LED hijau untuk pompa air. Hasil pengujian diperlihatkan pada Tabel 3. 
Tabel 3. Indikator Level Air

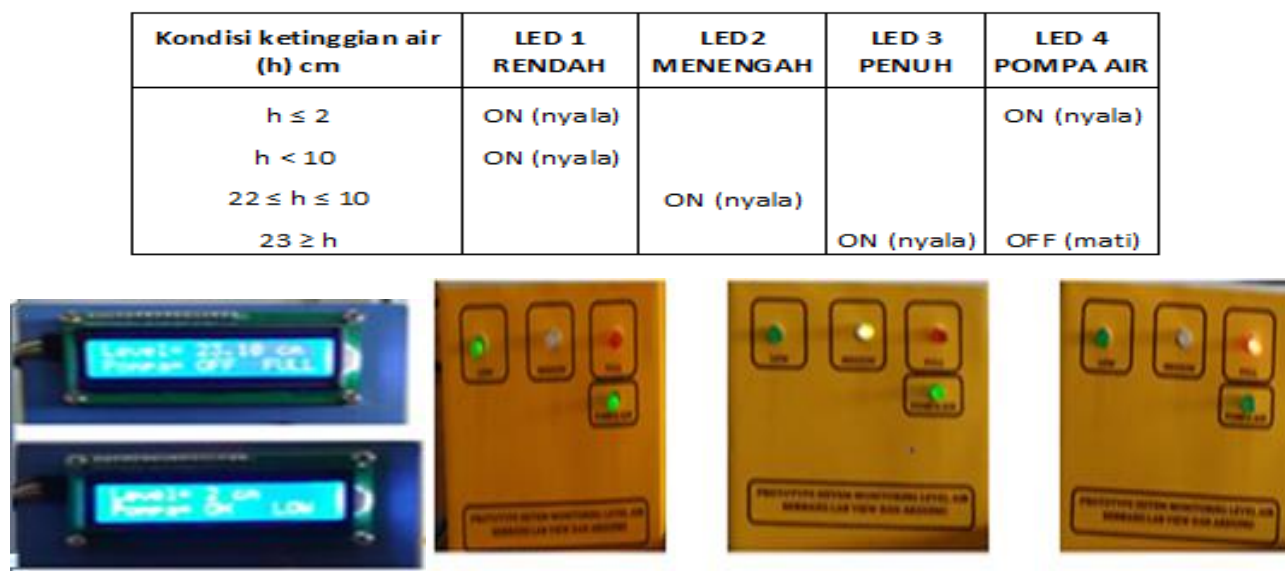

Gambar 20. Monitoring Dan Indikator Level Air

Pada Tabel 3 dan Gambar 20 menunjukan warna ketiga indikator LED, LED 1 hijau yaitu indikator hijau akan menyala apabila level air kurang dari 10 $\mathrm{cm}$, indikator hijau menginformasikan bahwa air dalam keadaan rendah, dan apabila level kurang dari atau sama dengan $2 \mathrm{~cm}$ LED hijau pompa air akan menyala menginformasikan bahwa tangki penampung air perlu diisi dan pompa air hidup, LED 2 kuning yaitu indikator akan menyala apabila level air antara $10-22 \mathrm{~cm}$, indikator kuning menginformasikan bahwa air dalam keadaan menengah, LED 3 merah yaitu indikator merah akan menyala apabila level air lebih dari atau sama dengan 23 $\mathrm{cm}$, indikator merah menginformasikan bahwa air dalam keadaan penuh dan menghentikan pompa air.

\section{KESIMPULAN DAN SARAN Kesimpulan}

Dari pembahasan hasil penelitian sebagaimana disebutkan pada bagian sebelumnya, maka dapat diambil kesimpulan sebagai berikut:

1. Prototype sistem monitoring level air ini telah berhasil di rancang untuk bekerja sesuai yang diharapkan.

2. Aplikasi sistem monitoring level air berbasis Lab VIEW dan Arduino ini dapat memberikan informasi dalam pemonitoringan level air secara real time, sehingga sistem tersebut dapat mengurangi kesalahan dalam pengisian tangki penampung air.

3. Perbedaan antara level air pada tangki dengan monitoring oleh sensor SRF05 sangat kecil dengan rata-rata kesalahan sebesar $0.089 \mathrm{~cm}$.

4. $L C D$ dan LabView pada rancang bangun monitoring ketinggian air ini dapat berfungsi dengan baik yaitu mampu menampilkan hasil dari data yang di baca

oleh sensor ultrasonik SRF05

5. Sensor ultrasonik SRF05 dalam membaca suatu objek berupa cairan mudah terganggu oleh noise, karena suatu cairan mengalami osilasi atau bergelombang yang membuat pembacaan sensor berubah ubah.

\section{Saran}

Dari hasil penelitian sistem ini tidak lepas dari kekurangan dan kelemahan. Oleh karena itu, saran yang dapat digunakan sebagai acuan dalam penelitian atau pengembangan selanjutnya, yaitu perlu dilakukan pengembangan penelitian dengan 
menggunakan komunikasi via wireless IOT (Internet of Things) sebagai sistem monitoring.

\section{DAFTAR PUSTAKA}

Abdul Kodir,"Buku Pintar Pemrograman Arduino", MediaKom,Yogyakarta,2014

Arif Ainur Rafiq, "Implementasi LabVIEW Sebagai Interface Dengan Arduino Uno Untuk Kontrol dan Monitoring Jarak, Suhu dan Pergerakan 2WD Mobile Robot", CITEE Bali, 2018

Budiono, E. "Programable Automation Controller dengan Lab VIEW 7.1 Terkoneksi Mikrokontroller dan PLC", Gava Media

Leonardo Robert Valentino,"Simulasi Aplikasi Monitoring Ketinggian Level Air Menggunakan Sensor Ultrasonik HC-SR04", Artikel IImiah, Universitas Kristen Satya Wacana, Agustus 2012

Palapa Wijaya, Yusmar. "Simulasi Pengendalian Volume Tangki Menggunakan LabVIEW dan Arduino Uno", Jurnal Sains, Teknologi dan Industri, Vol 13 No.1, pp.79-82, Desember 2015

Sumardi Sadi dan Ilham Syah Putra, "Rancang Bangun Monitoring Ketinggian Air Dan Sistem Kontrol Pada Pintu Air Berbasis Arduino dan Sms GateWay" Jurnal Teknik: Universitas Muhammadiyah Tangerang, Vol. 7, No. 1, Januari Juni, Tahun 2018: hlm. 77-91

Sutono, "Sistem Monitoring Ketinggian Air", Majalah IImiah UNIKOM Vol.13 No.1 